\title{
Synchronous solitary metastasis in renal cell carcinoma
}

\author{
Dr.J.V.Hardikar \\ Faculty of Medicine, AIMST university Malaysia
}

\begin{abstract}
This is the report of unusual case of synchronous splenic metastasis from renal cell carcinoma. Patient presented with hematuria and renal mass.The CT scan revealed renal cell carcinoma along with mass in the spleen suggestive of splenic metastasis .Patient underwent $(L)$ Radical nephrectomy along with splenectomy. The patient was disease free for a period of two years; subsequently he was lost to follow up. Keywords: solitary met, renal cell carcinoma, Synchronous mets, splenic metastasis
\end{abstract}

\section{Introduction}

Metastasis to the spleen is infrequent but varies greatly from series to series (1.6 to $30 \%)$, depending on the thoroughness of examination and selection of cases ${ }^{(1)}$ The most common primary tumors which can give rise to secondaries in the spleen are lung cancer, melanoma ${ }^{(2)}$ and occasionally breast cancer in females. It is unusual to find isolated splenic lesions from solid organ malignancies, with fewer than 25 cases reported worldwide ${ }^{[3]}$. Spread from renal cell carcinoma (RCC) is extremely unusual. In the reported case, there were synchronous lesions in the kidney and the spleen.

\section{Case report}

A 29 year old male patient reported with painless intermittent hematuria for a period of two months .There were no other constitutional symptoms like fever, malaise and weight loss .Clinical examination detected a mass in the (L) flank which was mildly tender. .Ultrasound examination showed a mass in the (L) kidney and the spleen. The patient underwent further evaluation with CT scan (Fig1 and 2) which showed renal and splenic masses. The other hematological investigations and X-ray chest were normal. There was no evidence of regional lymphadenopathy or bony metastasis.

The patient underwent exploration through a generous midline incision. The spleen was enlarged due to presence of mass in it Splenectomy and (L) radical nephrectomy were carried out. The post operative period was uneventful .Histopathology reported as clear cell carcinoma of kidney with involvement of peri renal fat. The splenic histology did confirm the metastasis from renal cell carcinoma.

The patient did follow up for a period for two years during which time he remained asymptomatic. Afterwards he was lost to follow up.

\section{Discussion:}

A splenic mass without any history of malignancy suggests a primary lesion such as lymphoma, vascular tumors, tropical splenomegaly in endemic areas or infectious lesions. Any past or present history of malignancy however should lead to a high index of suspicion for splenic metastasis .One should also consider rarer lesions such as hamartoma and inflammatory pseudotumour, which can both clinically and radiologically mimic a metastatic tumor in a case of isolated lesion in the spleen.

One should also consider the possibility of secondary involvement of the spleen through direct invasion, for example from a RCC in cases of concomitant enlargement of spleen and the kidney.

There are only eight reported cases of splenic metastasis from renal cell carcinoma ${ }^{(4)}$.Most of them were metachronus .the case reported by J.A.G. Moir, ${ }^{(5),{ }^{*}}$ etal is also a metachronus lesion in the spleen which developed after 11 months following radical nephrectomy for renal cell carcinoma. The incidence of isolated synchronous splenic metastasis from any given primary is also particularly rare.

Splenic metastases were previously considered exceptionally rare, however more recent advances in radiological imaging and the increased follow-up of patients with cancer means that the rate of detection has increased

The reason for the relative rarity of splenic metastases might be explained by several reasons (1) high velocity of constant blood flow through the spleen and rhythmic contraction of spleen prevents implantation of malignant cells within it .The tortuosity of splenic artery also impedes the large clumps of cells reaching the spleen (2) Lack of afferent lymphatic vessels limiting lympho genic metastases, and (3) the inhibitory effect of the splenic microenvironment on the growth of metastatic cells ${ }^{(5)}$ 
18 FDG PET scan can differentiate benign and malignant lesions of the spleen ${ }^{;(6)}$ however we did not carry out PET scan in our case. The lesion in the spleen was considered as metastatic and splenectomy was carried out.

The majority of splenic metastases are part of a multi-visceral metastatic disease, and the detection is often made soon after diagnosis of the primary tumour (mean duration after detection of primary tumour is 6.7 months), however this is often late in the course of disseminated disease ${ }^{(7)}$

\section{Conclusion}

The incidence of a solitary splenic metastasis from a RCC is particularly rare. They are often asymptomatic and picked up either incidentally or on surveillance imaging for previous malignancy. A splenectomy is an effective and safe option for symptomatic relief and prevention of future complications

\section{References:}

[1]. Schön CA, Görg C, Ramaswamy A, Barth PJ. Splenic metastases in a large unselected autopsy series. Pathol Res Pract. 2006;202:351-356

[2]. De Wilt JH, McCarthy WH, Thompson JF Surgical treatment of splenic Metastases in patients with melanoma. J Am Coll Surg. 2003 Jul; 197(1):38-43

[3]. Koh YS, Kim JC, Cho CK. Splenectomy for solitary splenic metastasis of ovarian cancer. BMC Cancer. 2004;4:96.

[4]. J.A.G. Moir,a* G. Sen,a R. Saif,a B. Haugk,b and J.J. Frencha Isolated Splenic Metastasis from Renal Cell Carcinoma: Case Report and Review Case Rep Gastroenterol. 2011 Jan-Apr; 5(1): 166-171.

[5]. AMA De Schepper ,F.Vanhoenacker Medical Imaging of the spleen Springer publication Verlag Berlin Heidelberg 2000 Page 165.

[6]. Metser U, Miller E, Kessler A, Lerman H, Lievshitz G, Oren R. Solid splenic masses: evaluation with 18F-FDG ET/CT. J Nucl Med. 2005;46:52-59. [PubMed]

[7]. Lam KY, Tang V: Metastatic tumors to the spleen. A 25-year clinicopathologic study. Arch Pathol Lab Med 2000;124:526-530

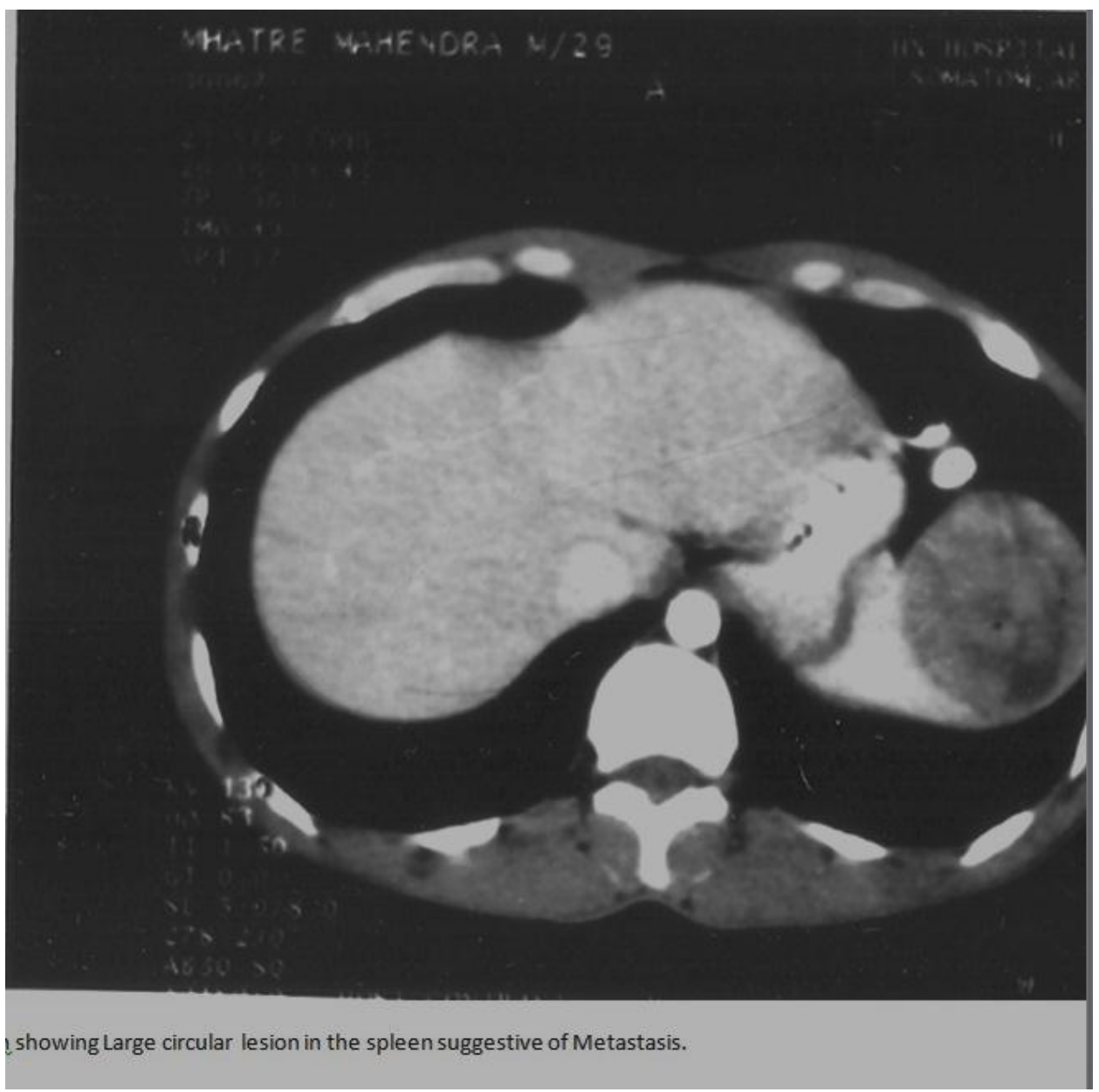

Fig1 showing large circular lesion in the spleen suggestive of metastasis 


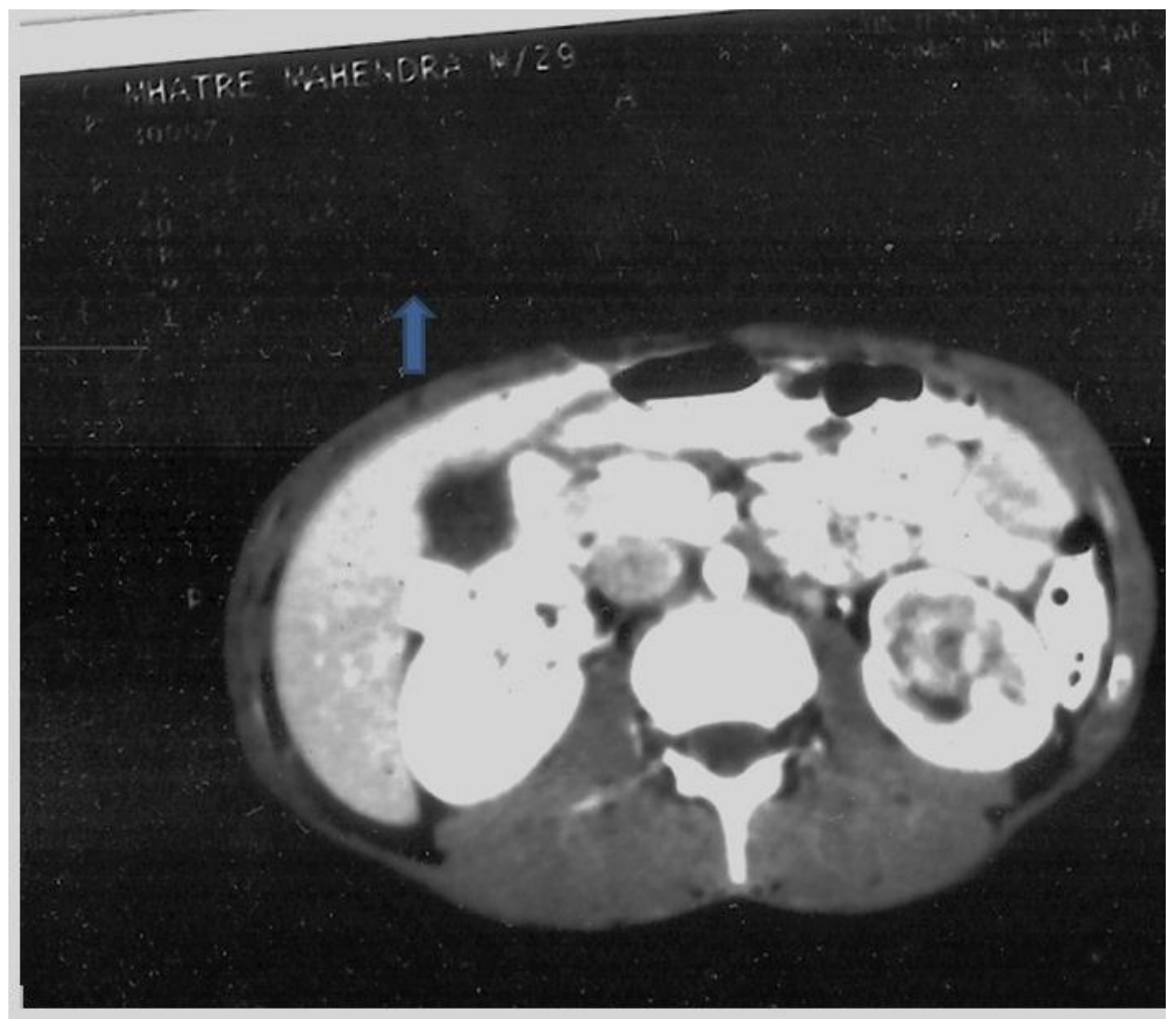

Fig.2 CT scan shows (L) renal cell carcinoma. 